\title{
Novel strategies for comprehensive mutation screening of the APC gene
}

\author{
Minireview \\ L. WACHSMANNOVA ${ }^{1, *}$, M. MEGO $^{2}$, V. STEVURKOVA ${ }^{1}$, V. ZAJAC ${ }^{1}$, S. CIERNIKOVA ${ }^{1}$ \\ ${ }^{1}$ Department of Genetics, Cancer Research Institute BMC, Slovak Academy of Sciences, Bratislava, Slovakia; ${ }^{2}$ Department of Medical Oncology, \\ Faculty of Medicine, Comenius University and National Cancer Institute, Bratislava, Slovakia \\ *Correspondence: exonlmat@savba.sk
}

Received December 19, 2016/ Accepted February 17, 2017

\begin{abstract}
Colorectal cancer is the 4th most common cause of cancer related deaths worldwide and new possibilities in accurate diagnosis and targeted treatment are highly required. Mutations in adenomatous polyposis coli (APC) gene play a pivotal role in adenoma-carcinoma pathway of colorectal tumorigenesis. The quarter century from its' first cloning, APC became one of the most frequently mutated, known driver genes in colorectal cancer. Intensive routine molecular testing of APC has brought the benefits for patients with family history of polyposis or colorectal cancer. Nevertheless, multiple mutational disease-causing mechanisms make the genetic testing still challenging. This minireview is focused on implementation of novel APC mutation screening diagnostic strategies for polyposis families according to the current findings. A further understanding and improved algorithms may help to increase the mutation detection rate. APC germline mutations achieve close to $100 \%$ penetrance, so more comprehensive approach followed by preventive and therapeutic strategies might reflect in decrease in burden of colorectal cancer.
\end{abstract}

Key words: colorectal cancer, familial adenomatous polyposis, large deletions, noncoding mutations, molecular diagnostic algorithms

\section{Familial adenomatous polyposis and $A P C$ gene}

Colorectal cancer (CRC) is the third most common cancer in men and the second most common cancer in women [1]. About $70 \%$ of all CRCs represent sporadic cases, developed due to the somatic mutations. Familial predisposition account for $10-30 \%$, whereas hereditary diseases present about $5-7 \%$ of all CRCs [2]. Well-described form of hereditary CRC is familial adenomatous polyposis (FAP; [MIM 175100]) characterized by hundreds to thousands (classic FAP) or less than one hundred colorectal adenomas (attenuated FAP, AFAP). Apart from colorectal adenomas, extracolonic manifestations such as desmoids tumors, osteomas, dental abnormalities, congenital hypertrophy of the retinal pigment epithelium (CHRPE), lipomas, epidermoid cysts and uppergastrointestinal polyps may also develop in patients with FAP [3]. In 2003, a genetically distinct type of AFAP has been identified, called MAP for MUTYH-associated polyposis (MIM 608456) [4]. The phenotype is similar to the AFAP, but the mode of inheritance is more complicated and the patients with MAP have fewer adenomatous polyposis (generally $>100$ ), later age of onset of adenomatous polyposis and colorectal cancer than classic FAP [5].

FAP is caused by dominant inheritance of germline mutations in the adenomatous polyposis coli (APC) tumor suppressor gene localized on chromosome 5q21-22. It encodes several tissue specific transcript in which the major transcript has an open reading frame of $8543 \mathrm{bp}$ [6]. The APC gene has two promoters, $1 \mathrm{~A}$ and $1 \mathrm{~B}$, which generate different mRNA products and appear to undergo tissue-specific regulation $[7,8]$. Promoter $1 \mathrm{~B}$ is located approximately $30 \mathrm{~kb}$ upstream of promoter $1 \mathrm{~A}$. APC promoter $1 \mathrm{~A}$ is down-regulated through hypermethylation in healthy gastric mucosa and gastric cancers [9]. Rohlin et al. showed that significant levels of transcript 
are generated from promoter $1 \mathrm{~B}$ in blood and in colorectal mucosa, as well as in a number of additional normal tissues. They estimated absolute levels of expression from promoter $1 \mathrm{~B}$ to be 25 - and 250 -fold higher compared with two different transcript generated from $1 \mathrm{~A}$ in normal colorectal mucosa and 100- and 1000-fold higher for each transcript in blood. It is thus established that promoter $1 \mathrm{~B}$ has an important role in the regulation of $A P C$ in a variety of normal tissues [7].

APC is a large scaffold protein with multiple binding partners and function, ubiquitiously expressed in a variety of tissues, including the brain and gastrointestinal tract. It is a key regulator of the oncogenic protein $\beta$-catenin in the Wnt signaling pathway. Failure to control cytosolic levels leads to an increase in nuclear $\beta$-catenin levels, where it binds to transcription factors and facilitates tumorigenesis. In addition to maintaining $\beta$-catenin concentration, APC is also a regulator of mictotubules (MTs) and APC mutations influence MT stability, growth [10], cell migration, adhesion, apoptosis and DNA repair [11]. Deletion of APC is also linked with intellectual and autistic disorders. Mohn and colleagues elucidate the importance of APC in the mammalian brain by showing that it is an essential regulator of both synaptic adhesion complexes and signal transduction networks [12]. While it is known that both mutant and full-lenght forms of APC locate at centrosomes, there are major gaps in our understanding of the targeting, dynamics and regulation of APC in this structure. The dynamic profile of APC at the centrosome was surprisingly unaffected by loss of the Cterminal half ( 1534 amino acid) of the protein, indicating that all the key sequences that mediate transient and strong protein associations reside within the $\mathrm{N}$-terminal region of APC [13]. C-terminus is predicted to assemble additional protein complexes required to regulate MT nucleation [14] and other activities.

\section{Mutation spectrum of the $A P C$ gene}

Over 1500 mutations have already been identified [15], with some genotype-phenotype correlations published in the literature $[16,17]$. Novel mutations are still being reported showing approximately $15 \%$ to $20 \%$ of FAP patients have de novo germline mutations [18]. The most common $A P C$ mutations in FAP patients are base substitutions and small deletions representing $36 \%$ and $43 \%$, respectively (Figure 1 ). About $60 \%$ of the $A P C$ mutations in colorectal tumors are clustered in the central domain of APC (amino Acids 1284-1580), also called the mutation cluster region (MCR) [19]. APC mutation within the MCR results in a truncated APC protein that lacks all of the axin binding sites and all but one or two of its 20 -amino acid $\beta$-catenin binding sites. There are two hotspots for germline mutations at codons 1061 and 1309, and another two hotspots for somatic mutations at codons 1309 and 1450 [20]. In accordance, our previous results showed the most frequent mutations in tested Slovak FAP families were located within codons 1309 and 1061 represented $15 \%$ and $7 \%$, respectively. Moreover, the expressive

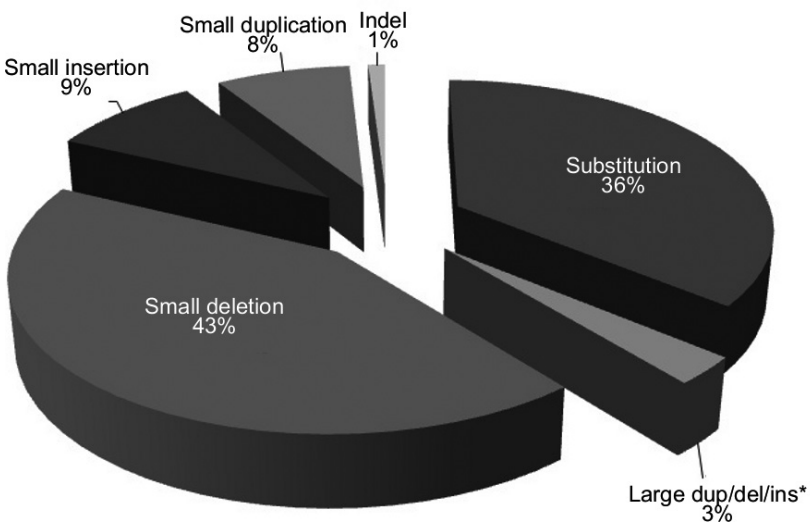

Figure 1. Frequency of APC mutations according to the InSiGHT Colon Cancer Gene Variant Databases

(http://chromium.lovd.nl/LOVD2/colon_cancer/home.php?select $\mathrm{db}=\mathrm{APC}$ ), last updated February 04, 2016.

* large dup/del/ins - large duplications/deletions/insertions

phenotype, large amount of colorectal polyps and congenital hypertrophy of the retinal pigment epithelium (CHRPE) were associated to all mutations within both these codons [21]. The vast majority of $A P C$ gene variations result in the expression of truncated protein that might have a dominant-negative, or gain-of-function, effect at least in the colon. Nontruncating single-base substitutions in the coding $A P C$ sequence or unique variants in less conserved intronic regions close to the splice sites have rarely been reported in FAP. Most of these APC variants are pathogenic due to aberrant splicing [22]. Recent data suggest that gross alterations in the APC gene may have been underreported initially, with up to $20 \%$ of FAP families potentially carrying a gross alteration [23]. However, the frequency of pathogenic APC mutations is very high compare to variants with non-significant relevance (Figure 2).

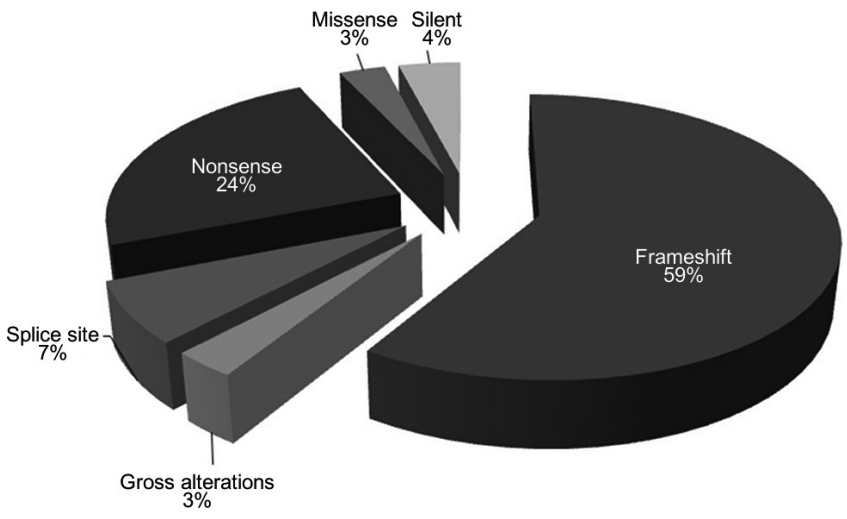

Figure 2. Molecular consequences of APC variants according to the InSiGHT Colon Cancer Gene Variant Databases

(http://chromium.lovd.nl/LOVD2/colon_cancer/home.php?select_ $d b=A P C)$, last updated February 04, 2016 


\section{Large deletions in noncoding regions of the $A P C$ gene}

APC gene was cloned in 1991 and since then worldwide establishment of molecular-genetic screening in patients at risk took place. However, $20 \%$ of classical FAP and $70 \%$ of AFAP cases remain mutation-negative after routine testing [16]. Mutations in APC noncoding regions, such as intronic mutations or promoter regions and in other causative genes like MUTYH, combined with older testing technologies account for some of the undetected mutations. Introduction of multiplex ligation-dependent probe amplification (MLPA), large but submicroscopic genomic APC deletions were more readily detected and are recognized to constitute around $12 \%$ of FAP cases [24]. The introduction of next generation sequencing using whole-genome sequencing, whole-exome sequencing and multigene panels have made it possible to identify a spectrum of new mutations and also new causative genes in hereditary CRC. Zhang et al. identified by next generation sequencing a novel heterozygous large deletion (c.423_8532del) of the APC gene. This is the first reported large deletion in the Chinese population associated with FAP [25]. Large deletions could be detected using microarray-based comparative genomic hybridization (array CGH). In this method patient and control DNA samples should be labeled with different florescent dyes [26].

Charames et al. described a single family with a large deletion containing promotor $1 \mathrm{~A}$, associated with complete silencing of the deletion-containing allele. Owing to the lack of promoter 1B-specific probes, it remains unsettled whether or not the deletion also affected promoter 1B. The mechanism of allelic silencing could not be determined at the time [27]. Rohlin et al. described a $\sim 61 \mathrm{~kb}$ heterozygous deletion which resulted in reduction in expresion (approximatelly 90\%), but not silencing, of the APC allele [7]. This deletion affects an open reading frame within it. Lin et al. found $\sim 11 \mathrm{~kb}$ deletion, encompasses exon $1 \mathrm{~B}$ and promoter $1 \mathrm{~B}$, which silenced one APC allele in affected individuals [28]. Pavicic et al. found that a large deletion of $132 \mathrm{~kb}$ resulted in a reduction of the deleterious allele expression to $40-60 \%$ of the wild-type allele [29]. Yamaguchi et al. identified a deletion of $\sim 10 \mathrm{~kb}$ encompassing the promoter $1 \mathrm{~B}$ resulted in a marked decrease of $A P C$ transcripts in spite of the remaining $A P C-1 A$ transcript. This deletion caused $87 \%$ reduction of mutant allele expression. Although deletions of promoter $1 \mathrm{~B}$ reduced the expression of mutant APC allele, the degree of reduction caused by the deletions is different. Interestingly, the residual transcription was maintained by promoter $1 \mathrm{~A}$ although the activity of promoter $1 \mathrm{~B}$ was completely lost [30]. This compensatory mechanism against the impaired activity of promoter $1 \mathrm{~B}$ has been reported by Rohlin et al. and Yamaguchi et al. [7,30].

In colorectal carcinomas, methylation of promoter $1 \mathrm{~A}$ is presented in $20-45 \%$ of tumors [31,32] whereas promoter $1 \mathrm{~B}$ is not prone to aberrant methylation [33]. The phenotype of classical FAP with no extracolonic manifestations appears common to all three families with promoter $1 \mathrm{~B}$ deletions
$[7,29,34]$. Due to the small sample size it would not be appropriate to speculate about genotype-phenotype correlation. Snow et al. speculate that the loss of expression from the $A P C$ promoter $1 \mathrm{~B}$ deletion allele combined with low levels of promoter $1 \mathrm{~A}$ expression may modify the presence of gastric and duodenal polyps [35]. Point mutation in the promoter $1 \mathrm{~B}$ of $A P C$ [36] and description of gastric polyposis and gastric cancer in some individuals with large deletions around the promoter $1 \mathrm{~B}[7,28,29,34,35]$, suggest that families with alternations in the promoter $1 \mathrm{~B}$ are at risk of gastric adenocarcinoma. Li et al. study show that specific point mutations in the Yin Yang 1 (YY1) binding site in the promoter 1B of $A P C$ are the cause of gastric adenocarcinoma and proximal polyposis of the stomach (GAPPS), a new and potentially severe variant of FAP [36]. YY1 is a ubiquitously expressed transcription factor that has been shown to have multiple roles in oncogenesis and can act as both an activator and repressor of transcription [37].

\section{Molecular diagnostic algorithms for polyposis families}

Imbalance in allele-specific expression (ASE) of the two $A P C$ alleles as a cause of FAP has been recognized in several families [38]. Reduced ASE of the APC gene has been shown to be associated with a predisposition to FAP. The degree of expression reduction for one allele has been variable, ranging from around $50 \%$ to complete silencing $[38,39]$. Castellsagué et al. propose a molecular diagnostic algorithm for polyposis families that undergo APC mutation screening beginning with analysis of gross rearrangements. In samples with ASE imbalance, sequencing of exons 1-14 at the cDNA or gDNA level would be followed by analysis of the promoter region and, possibly, the 3'UTR region. This strategy would have made it unnecessary to sequence the largest exon of the gene (exon 15) [38]. In contrast Hegde et al. recommended that FAP testing be performed using full sequencing of the $A P C$ gene. If no mutation is detected, then testing for large gene rearrangements should be performed [23]. It is difficult to say, which algorithm is better. Comprehensive analysis of the entire APC gene is necessary for diagnostic testing of FAP. A mutation is detected in $\sim 80 \%$ of patients with a clinical diagnosis of FAP, with DNA sequencing detecting $87 \%$ of point mutations and small insertions or deletions [40]. The remaining $10-15 \%$ of mutations represents gross deletions and duplications, which can be detected by MLPA, Southern blot, or real-time quantitative PCR analysis. Recently, New Generation Sequencing (NGS) techniques afford the opportunity to screen patients for a comprehensive panel of colorectal cancer susceptibility genes in a cost-effective fashion [41].

\section{Targeted therapy and prognostic role of the APC gene}

$A P C$ was presumed to be an important „initiator" gene for the majority of CRCs $[42,43]$. The Cancer Genome Atlas (TCGA) project has profiled and characterized the landscape 
of CRC mutations. In $94 \%$ of analysed samples, a mutation in one or more members of the WNT signaling pathway occurred, mainly the APC gene [44]. Yu et al. successfully affirmed $A P C$ as one of the most frequently mutated genes by validation of 187 recurrent and pathway-related genes in analyzed colon cancer series [45]. Classical tumor progression model $A P C \rightarrow K R A S \rightarrow T P 53$ is a widely perceived sequential pathway of the key driver mutation events commonly occurring in CRC development $[43,46]$. The analysis performed on 468 colorectal tumor samples across 1321 genes associated with human cancer revealed that $A P C$ mutation usually cooccurs with either KRAS or TP53 mutations or both [47]. This suggesting that $A P C$ mutations need to make a partnership with one or more additional driver mutations to advance to CRCs. Our results showed the presence of truncating APC mutation in codon 1060 together with p53 mutation in codon 210 in FAP patient with extraordinary expressive phenotype [48]. While APC mutations did not affect survival in a cohort of 107 CRC patients [49], a novel prognostic, five-class multigene mutation classification system comprising $A P C$ to play a central role in the context of its partnering mutations (with KRAS and TP53) and its bi-allelic mutation status has been developed [47].

Despite the prevalence of APC truncations in CRC, there are currently no therapeutics directly targeting them. Zhang et al. identified a candidate small molecule, TASIN-1 (truncated APC selective inhibitor-1), which specifically kills CRC cell lines with truncated APC through induction of apoptotic cell death. TASIN-1 inhibits cancer cell growth in human tumor xenografts and in a genetically engineered mouse model of CRC [50]. Considering the high prevalence of APC mutations in patients with CRC, targeting truncated APC should be an efefctive therapeutic strategy for prevention and intervention of CRC and a potential marker for stratifying patients in future personalized medicine clinical trials.

\section{Conclusion}

APC gene size, allelic and locus heterogenity, and multiple mutational disease-causing mechanisms continue to make the detection of disease-causing mutations in patients with colorectal adenomatous polyposis challenging. Technological advances as whole-genome sequencing in combination with ASE analysis by deep sequencing may be a useful strategy to identify deleterious genetic alterations in the regulatory regions undetected by routine genetic screening. Although genetic risk of FAP can be evaluated through mutation testing, refined correlations between specific mutations and clinical phenotypes remain limited and still do not provide the guidance for the clinical management of patients with FAP disease. Moreover, recent studies point to possible prognostic role of $A P C$ in tumor evolution. Comprehensive approach and development of multigene CRC classification systems might help to identify appropriate therapy for subpopulations of cancer patients.
Acknowledgements: This article and our experiments mentioned in this minireview were performed with the kind support provided by the grants VEGA 2/0170/13, VEGA 2/0029/15 and VEGA 2/0099/17.

\section{References}

[1] ARMAGHANY T, WILSON JD, CHU Q, MILLS G. Genetic alterations in colorectal cancer. Gastrointest Cancer Res 2012; 5: 19-27.

[2] DE ROSA M, PACE U, REGA D, COSTABILE V, DURATURO F et al. Genetics, diagnosis and management of colorectal cancer (Review). Oncol Rep 2015; 34: 1087-1096. https://doi.org/10.3892/or.2015.4108

[3] JANG YH, LIM SB, KIM MJ, CHUNG HJ, YOO HW et al. Three novel mutations of the APC gene in Korean patients with familial adenomatous polyposis. Cancer Genet Cytogenet 2010; 200:34-39. https://doi.org/10.1016/j.cancergencyto.2010.03.015

[4] ARETZ S, GENUARDI M, HES FJ. Clinical utility gene card for: MUTYH- associated polyposis (MAP), autosomal recessive colorectal adenomatous polyposis, multiple colorectal adenomas, multiple adenomatous polyps (MAP) - update 2012. Eur J Hum Genet 2013; 21. doi: 10.1038/ejhg.2012.163 https://doi.org/10.1038/ejhg.2012.163

[5] SAMPSON JR, JONES N. MUTYH-associated polyposis. Best Pract Res Clin Gastroenterol 2009; 23: 209-218. https://doi. org/10.1016/j.bpg.2009.03.006

[6] HORII A, NAKATSURU S, ICHII S, NAGASE H, NAKAMURA Y. Multiple forms of the APC gene transcripts and their tissue-specific expression. Hum Mol Genet 1993; 2: 283-287. https://doi.org/10.1093/hmg/2.3.283

[7] ROHLIN A, ENGWALL Y, FRITZELL K, GORANSSON $\mathrm{K}, \mathrm{BERGSTEN} \mathrm{A}$ et al. Inactivation of promoter $1 \mathrm{~B}$ of APC causes partial gene silencing: evidence for a significant role of the promoter in regulation and causative of familial adenomatous polyposis. Oncogene 2011; 30: 4977-4989. https:// doi.org/10.1038/onc.2011.201

[8] HOSOYA K, YAMASHITA S, ANDO T, NAKAJIMA T, ITOH F, USHIJIMA T. Adenomatous polyposis coli $1 \mathrm{~A}$ is likely to be methylated as a passenger in human gastric carcinogenesis. Cancer Lett 2009; 285: 182-189. https://doi.org/10.1016/j. canlet.2009.05.016

[9] CLEMENT G, BOSMAN FT, FONTOLLIET C, BENHATTAR J. Monoallelic methylation of the APC promoter is altered in normal gastric mucosa associated with neoplastic lesions. Cancer Res 2004; 64: 6867-6873. https://doi. org/10.1158/0008-5472.CAN-03-2503

[10] NATHKE I. Cytoskeleton out of the cupboard: colon cancer and cytoskeletal changes induced by loss of APC. Nat Rev Cancer 2006; 6: 967-974. https://doi.org/10.1038/nrc2010

[11] JAISWAL AS, NARAYAN S. A novel function of adenomatous polyposis coli (APC) in regulating DNA repair Review Article Cancer Lett. 2008; 271: 272- 280. https://doi.org/10.1016/j. canlet.2008.06.024

[12] MOHN JL, ALEXANDER J, PIRONE A, PALKA CD, LEE SY et al. Adenomatous polyposis coli protein deletion leads to cognitive and autism-like disabilities. Mol Psychiatry 2014; 19: 1133-1142. https://doi.org/10.1038/mp.2014.61 
[13] LUI C, MOK MT, HENDERSON BR. Characterization of Adenomatous Polyposis Coli Protein Dynamics and Localization at the Centrosome. Cancers (Basel) 2016; 8 .

[14] LUI C, ASHTON C, SHARMA M, BROCARDO MG, HENDERSON BR. APC functions at the centrosome to stimulate microtubule growth. Int J Biochem Cell Biol 2016; 70: 39-47. https://doi.org/10.1016/j.biocel.2015.10.028

[15] http://www.hgmd.cf.ac.uk/ac/gene.php?gene=APC

[16] FRIEDL W, ARETZ S. Familial adenomatous polyposis: experience from a study of 1164 unrelated german polyposis patients. Hered Cancer Clin Pract 2005; 3: 95-114. https:// doi.org/10.1186/1897-4287-3-3-95

[17] KERR SE, THOMAS CB, THIBODEAU SN, FERBER MJ, HALLING KC. APC germline mutations in individuals being evaluated for familial adenomatous polyposis: a review of the Mayo Clinic experience with 1591 consecutive tests. J Mol Diagn 2013; 15: 31-43. https://doi.org/10.1016/j.jmoldx.2012.07.005

[18] BISGAARD ML, FENGER K, BULOW S, NIEBUHR E, MOHR J. Familial adenomatous polyposis (FAP): frequency, penetrance, and mutation rate. Hum Mutat 1994; 3: 121-125. https://doi.org/10.1002/humu.1380030206

[19] VAN ES JH, GILES RH, CLEVERS HC. The many faces of the tumor suppressor gene APC. Exp Cell Res 2001; 264: 126-134. https://doi.org/10.1006/excr.2000.5142

[20] BEROUD C, SOUSSI T. APC gene: database of germline and somatic mutations in human tumors and cell lines. Nucleic Acids Res. 1996; 24: 121-124. https://doi.org/10.1093/ $\underline{\text { nar/24.1.121 }}$

[21] ZAJAC V, KOVAC M, KIRCHHOFF T, STEVURKOVA V, TOMKA M. The most frequent APC mutations among Slovak familial adenomatous polyposis patients. Adenomatous polyposis coli. Neoplasma 2002; 49: 356-361.

[22] KAUFMANN A, VOGT S, UHLHAAS S, STIENEN D, KURTH I et al. Analysis of rare APC variants at the mRNA level: six pathogenic mutations and literature review. J Mol Diagn 2009; 11: 131-139. https://doi.org/10.2353/ jmoldx.2009.080129

[23] HEGDE M, FERBER M, MAO R, SAMOWITZ W, GANGULY A et al. ACMG technical standards and guidelines for genetic testing for inherited colorectal cancer (Lynch syndrome, familial adenomatous polyposis, and MYH- associated polyposis). Genet Med 2014; 16: 101-116. https:// doi.org/10.1038/gim.2013.166

[24] ARETZ S, STIENEN D, UHLHAAS S, PAGENSTECHER C, MANGOLD E et al. Large submicroscopic genomic APC deletions are a common cause of typical familial adenomatous polyposis. J Med Genet 2005; 42: 185-192. https://doi. org/10.1136/jmg.2004.022822

[25] ZHANG Z, LIANG S, HUANG H, WANG D, ZHANG X et al. A novel pathogenic large germline deletion in adenomatous polyposis coli gene in a Chinese family with familial adenomatous polyposis. Oncotarget 2016; 7: 50392-50400.

[26] NALLAMILLI BR, HEGDE M. Detecting APC Gene Mutations in Familial Adenomatous Polyposis (FAP). Curr Protoc Hum Genet 2017; 92: 10.8.1-10.8.16.

[27] CHARAMES GS, RAMYAR L, MITRI A, BERK T, CHENG $\mathrm{H}$ et al. A large novel deletion in the APC promoter region causes gene silencing and leads to classical familial adenomatous polyposis in a Manitoba Mennonite kindred. Hum Genet 2008; 124: 535-541. https://doi.org/10.1007/s00439$\underline{008-0579-4}$

[28] LIN Y, LIN S, BAXTER MD, LIN L, KENNEDY SM et al. Novel APC promoter and exon 1B deletion and allelic silencing in three mutation- negative classic familial adenomatous polyposis families. Genome Med 2015; 7: 42. https://doi. org/10.1186/s13073-015-0148-0

[29] PAVICIC W, NIEMINEN TT, GYLLING A, PURSIHEIMO JP, LAIHO A et al. Promoter-specific alterations of APC are a rare cause for mutation-negative familial adenomatous polyposis. Genes Chromosomes Cancer 2014; 53: 857-864. https://doi. org/10.1002/gcc.22197

[30] YAMAGUCHI K, NAGAYAMA S, SHIMIZU E, KOMURA $\mathrm{M}$, YAMAGUCHI R et al. Reduced expression of APC-1B but not APC-1A by the deletion of promoter $1 \mathrm{~B}$ is responsible for familial adenomatous polyposis. Sci Rep 2016; 6: 26011. https://doi.org/10.1038/srep26011

[31] JOENSUU EI, ABDEL-RAHMAN WM, OLLIKAINEN M, RUOSAARI S, KNUUTILA $S$ et al. Epigenetic signatures of familial cancer are characteristic of tumor type and family category. Cancer Res 2008; 68: 4597-4605. https://doi. org/10.1158/0008-5472.CAN-07-6645

[32] SEGDITSAS S, SIEBER OM, ROWAN A, SETIEN F, NEALE $\mathrm{K}$ et al. Promoter hypermethylation leads to decreased APC mRNA expression in familial polyposis and sporadic colorectal tumours, but does not substitute for truncating mutations. Exp Mol Pathol 2008; 85: 201-206. https://doi.org/10.1016/j. yexmp.2008.09.006

[33] ESTELLER M, SPARKS A, TOYOTA M, SANCHEZCESPEDE M, CAPELLA G et al. Analysis of adenomatous polyposis coli promoter hypermethylation in human cancer. Cancer Res 2000; 60: 4366-4371.

[34] KADIYSKA TK, TODOROV TP, BICHEV SN, VAZHAROVA $\mathrm{RV}$, NOSSIKOFF AV et al. APC promoter 1B deletion in familial polyposis- implications for mutation-negative families. Clin Genet 2014; 85: 452-457. https://doi.org/10.1111/cge.12210

[35] SNOW AK, TUOHY TM, SARGENT NR, SMITH LJ, BURT RW et al. APC promoter 1B deletion in seven American families with familial adenomatous polyposis. Clin Genet 2015; 88: 360-365. https://doi.org/10.1111/cge.12503

[36] LI J, WOODS SL, HEALEY S, BEESLEY J, CHEN X et al. Point Mutations in Exon 1B of APC Reveal Gastric Adenocarcinoma and Proximal Polyposis of the Stomach as a Familial Adenomatous Polyposis Variant. Am J Hum Genet 2016; 98: 830-842. https://doi.org/10.1016/j.ajhg.2016.03.001

[37] ATCHISON M, BASU A, ZAPRAZNA K, PAPASANI M. Mechanisms of Yin Yang 1 in oncogenesis: the importance of indirect effects. Crit Rev Oncog 2011; 16(3-4): 143-161. https://doi.org/10.1615/CritRevOncog.v16.i3-4.20

[38] CASTELLSAGUE E, GONZALEZ S, GUINO E, STEVENS $\mathrm{KN}, \mathrm{BORRAS} \mathrm{E}$ et al. Allele-specific expression of APC in adenomatous polyposis families. Gastroenterology 2010; 139: 439-447. https://doi.org/10.1053/j.gastro.2010.04.047

[39] KANTER-SMOLER G, FRITZELL K, ROHLIN A, ENGWALL Y, HALLBERG B et al. Clinical characterization and the mu- 
tation spectrum in Swedish adenomatous polyposis families. BMC Med 2008; 6: 10. https://doi.org/10.1186/1741-7015-6-10

[40] GROVER S, KASTRINOS F, STEYERBERG EW, COOK EF, DEWANWALA A et al. Prevalence and phenotypes of APC and MUTYH mutations in patients with multiple colorectal adenomas. JAMA 2012; 308: 485-492. https://doi. org/10.1001/jama.2012.8780

[41] BUECHER B. Colorectal adenomatous polyposis syndromes: Genetic determinism, clinical presentation and recommendations for care. Bull Cancer. 2016; 103: 199-209. https://doi. org/10.1016/j.bulcan.2015.10.019

[42] FEARON ER. Molecular genetics of colorectal cancer. Annu Rev Pathol 2011; 6: 479-507. https://doi.org/10.1146/annurevpathol-011110-130235

[43] FEARON ER, VOGELSTEIN B. A genetic model for colorectal tumorigenesis. Cell 1990; 61: 759-767. https://doi. org/10.1016/0092-8674(90)90186-I

[44] CANCER GENOME ATLAS NETWORK. Comprehensive molecular characterization of human colon and rectal cancer. Nature 2012; 487:330-337. https://doi.org/10.1038/nature11252

[45] YU J, WU WK, LI X, HE J, LI XX et al. Novel recurrently mutated genes and a prognostic mutation signature in colo- rectal cancer. Gut 2015; 64: 636-645. https://doi.org/10.1136/ gutjnl-2013-306620

[46] MARKOWITZ SD, BERTAGNOLLI MM. Molecular origins of cancer: Molecular basis of colorectal cancer. N Engl J Med 2009; 361: 2449-2460. https://doi.org/10.1056/NEJM$\underline{\mathrm{ra} 0804588}$

[47] SCHELL MJ, YANG M, TEER JK, LO FY, MADAN A et al. A multigene mutation classification of 468 colorectal cancers reveals a prognostic role for APC. Nat Commun 2016; 7: 11743. https://doi.org/10.1038/ncomms11743

[48] ZAJAC V, TOMKA M, ILENCIKOVA D, MAJEK P, STEVURKOVA $V$ et al. A double germline mutations in the APC and p53 genes. Neoplasma 2000; 47: 335-341.

[49] CONLIN A, SMITH G, CAREY FA, WOLF CR, STEELE RJ. The prognostic significance of K-ras, p53, and APC mutations in colorectal carcinoma. Gut. 2005; 54: 1283-1286. https://doi. org/10.1136/gut.2005.066514

[50] ZHANG L, THEODOROPOULOS PC, ESKIOCAK U, WANG W, MOON YA et al. Selective targeting of mutant adenomatous polyposis coli (APC) in colorectal cancer. Sci Transl Med 2016; 8: 361ra140. https://doi.org/10.1126/scitranslmed.aaf8127 